\title{
Application of Two Level Count Regression Modeling on the Determinants of Fertility among Married Women in Ethiopia
}

Nuru Mohammed Hussen ( $\square$ nurediin5111@gmail.com )

Samara University

\section{Research Article}

Keywords: Ethiopia, Fertility, hierarchical data, multilevel count regression analysis.

Posted Date: August 18th, 2021

DOI: https://doi.org/10.21203/rs.3.rs-717309/v1

License: (c) (i) This work is licensed under a Creative Commons Attribution 4.0 International License.

Read Full License 


\title{
Application of Two Level Count Regression Modeling on the Determinants of Fertility among Married Women in Ethiopia
}

Nuru Mohammed Hussen ${ }^{1}$

${ }^{1}$ Samara University, Statistics Department, Samara, Ethiopia

nurediin5111@gmail.com

\begin{abstract}
Background: Fertility is the element of population dynamics that has a vital contribution towards changing population size and structure over time. The global population showed a major increment from time to time because of these dynamics, particularly in south Asia and sub-Saharan Africa including Ethiopia. So this study targeted on the factors affecting fertility among married women in Ethiopia through the framework of multilevel count regression analysis using EDHS 2016 data.
\end{abstract}

Methods: The sampling design for EDHS 2016 was a two-stage stratified cluster sampling design, where stratification was achieved by separating every region into urban and rural areas except the Addis Ababa region.

Results: Among the random sample of 6141 women in the country, 27150 births were recorded based on EDHS 2016 report. The histograms showed that the data has a positively skewed distribution extremely picked at the beginning. Two- level negative binomial regression model was fitted to spot out the determinants of fertility among married women in Ethiopia because it has the smallest value for the fit statistics and the variance of the data was higher than its mean.

Conclusion: Findings from the study revealed that contraception method used, residence, educational level of women, women's age at first birth, and proceeding birth interval were the 
major predictors of fertility among married women in Ethiopia. Moreover, the estimates from the random effect result revealed that there is more fertility variation between the enumeration areas than within the enumeration areas. Application of standard models by ignoring this variation ought to embrace spurious results, then multilevel modeling is recommended for such types of hierarchical data.

Keywords: Ethiopia, Fertility, hierarchical data, multilevel count regression analysis.

\section{Introduction}

Fertility is outlined as the actual kid- bearing performance of the population. It's the element of population dynamics that has a vital contribution towards dynamical population size and structure over time. The global population showed a five billion increment ( 2.6 billion to 7.6 billion) from 1950 to 2017 because of this dynamics, wherever most of this increment was higher in South Asia and sub- Saharan Africa relative to the remaining components of the globe [1].

The total population of Ethiopia was near to one hundred million, this makes it the second most inhabited country in Africa. High fertility rate is the basic character of Ethiopian population growth [2]. Among the overall population, $44.4 \%$ were beneath the age of fifteen years (CSA, 2016). In step with Ethiopia demographic and health survey (EDHS), the country's fertility rate shows slight decrement between 2000 and 2005, from 5.9 youngsters per woman to 5.4, so attenuated more to 4.8 youngsters in 2011 , then it reaches 4.6 in 2016 . The overall wanted fertility rate (TWFR) in Ethiopia is 3.0 youngsters per woman, 1.6 less than the total fertility rate in 2016 [3]. Even though fertility has shown a declining trend at the national level, the transition has not begun in several regions. There was clear regional variations in fertility levels and trends in Ethiopia. Like other developing countries, vital variation in fertility level was ascertained among rural and urban residents of Ethiopia. For example in keeping with the 2016 Ethiopian demographic and health 
survey report, on average, rural women can offer birth to just about 3 more kids throughout their generative years than urban women(5.2 versus 2.3 kids per woman) [4].

The Ethiopian government has been creating many efforts to cut back fertility levels since 1993 . The primary time a certain national population policy geared towards reducing the total fertility rate from 7.7 youngsters per woman to 4.0 by 2015 was launched[5]. Increasing age at first marriage to a minimum of eighteen years, enhancing women's standing through providing them with higher employment and academic opportunities, increasing birth control services and knowledge, communication, and education on the ways and suggests that limiting family size were some of the ways designed to implement the population program [6]. Fertility trends will be foreseen and an increase will be enrolled by recognizing the factors that affect fertility preferences and desires. Within the setting of the above circumstances, this study attempted to spot out the factors related to the total number of children ever born among married women in Ethiopia. Many studies investigated determinants of fertility in Ethiopia with some sets of variable and statistical methods like logistic regression, survival analysis, and linear regression models [7-10]. Since the total number of children ever born is a count data, the Poisson regression model (PRM) and Negative binomial regression models (NBRM) are shown to be statistically more acceptable. However, on the far side of the count nature of the data, it has hierarchical nature wherever women are nested beneath the enumeration area and every enumeration area were nested beneath the region. All the above standard statistical models and techniques have problems in handling the multilevel data structure, as an example in regression models violating the independence and normality assumption of errors with a constant variance [11-13]. Heteroscedasticity raises if the underlying dependency that comes attributable to the multilevel nature of the data isn't adjusted within the simple regression models. In such cases, multilevel models rather than standard models 
got to introduce for considering the direct impact of the individual and also group-level variables.

There are several studies that restricted multilevel models for the analysis of hierarchical data [14, 15]. Hence with respect to those pieces of literatures this study geared towards factors affecting fertility among married women in Ethiopia through the framework of multilevel analysis using EDHS 2016 data.

\section{Methods}

\section{Data source}

The present paper uses the data set from the 2016 Ethiopia Demographic and Health Survey (EDHS) which was the fourth demographic and health survey. EDHS was strengthened by the Central Statistical Agency (CSA) with support obtained from the Ministry of Health. This survey was carried out in Ethiopia, under the worldwide measure of DHS project, a USAID-funded project providing support and technical assistant with the enforcement of population and health surveys in countries worldwide.

\section{Sampling Design}

The sampling frame used for EDHS 2016 was the same as the sampling frame of EDHS 2007 which was previously conducted in 2007 by the Central Statistical Agency (CSA, 2008). This survey uses a census frame of 84,915 enumeration areas (EAs) created for the 2007 PHC. An EA could be defined as a geographic area covering a mean of 181 households. Administratively, Ethiopia is divided into 9 nation-states and 2 administrative cities. Every region is sub-divided into zones, every zone into Woredas, every woreda into cities, and every city into kebeles. The sampling design for EDHS 2016 was a two-stage stratified cluster sampling design. Stratification was conducted by separating every region into urban and rural areas. In total, 21 sampling strata were created as a result of the Addis Ababa region is entirely urban. Samples of EAs were selected independently in every stratum in 2 stages. Among the primary stage 645 selected EAs, 202 were urban and 443 were rural areas and in the second stage of selection, a fixed number of 28 
households per cluster were chosen through an equal probability systematic selection from the newly created household listing. Each one among women age 15-49 and each one among men aged 15-59, who were either permanent residents of the chosen households or visitors who stayed within the household the night prior to the survey, were able to be interviewed.

\section{Variables in the Study}

The response variable of this study was the total number of children ever born among married women in Ethiopia which is a count variable from the birth record dataset in EDHS 2016. However, the contraception method used, Women's educational level, Wealth index, Preceding birth interval, Religion, and Women's age at first birth were potential lower level, predictors of fertility, while the residence was a potentially higher level predictor of fertility. Secondary data was managed with SPSS-26 and analyzed using R-3.6.3 and SAS- 9.4. The model selection was made using LRT for nested, AIC, and BIC for non-nested models.

\section{Statistical analysis}

Count regression models analyses the data with integer outcome variables. These models may be used to look at the prevalence or frequency of prevalence over time. Various models were developed for the analysis of count data $[16,17]$. These models can handle non-normality on the dependent variable and do not require the researcher to either dichotomize or transform the dependent variable. This study had centered on the four most frequently used models; Poisson regression model, Negative Binomial models, Zero-inflated Poisson, and Zero- inflated Negative Binomial models [18, 19].

\section{Poisson Regression Model}

A Poisson regression model is the most popular model for count data, which is based on the property that the mean and variance of the dependent variable are assumed to be equal [20]. 
Let, $Y_{i}$ represent counts of events occurring in a given time or exposure periods with rate $\mu_{i}, Y_{i}$ are Poisson random variables with probability mass function;

$P\left(Y_{i}=\mu_{i}\right)=\frac{e^{-\mu_{i}} \mu^{y_{i}}}{y_{i} !} ; \mu_{i}>0, i=1,2, \ldots, n \quad y_{i}=0,1,2$,

Where $y_{i}$ denotes the total number of children ever born for the $i^{\text {th }}$ women in a given time or exposure periods with parameter $\mu_{i}$

In the Poisson model, the conditional variance is equal to conditional mean:

$E\left(Y_{i}\right)=\operatorname{Var}\left(Y_{i}\right)=\mu_{i}$

This property of the Poisson distribution is known as equi dispersion.

Let $\mathrm{X}$ be $n X(P+1)$ covariate matrix. The relationship between $Y_{i}$ and $i^{\text {th }}$ row vector of $\mathrm{X}, x_{i}$ is given by the Poisson log-linear model $\ln \left(\mu_{i}\right)=x_{i}^{T} \beta=\eta_{i}$

Where $x_{i}=\left\{1, x_{i 1}, x_{i 2}, \ldots, x_{i p}\right\}^{T}$ is the vector of explanatory variables and $\beta=\left(\beta_{0}, \beta_{1}, \ldots, \beta_{p}\right\}^{T}$ is the vector of unknown regression parameters.

\section{Negative Binomial Regression Model}

Most of the time, the count variable with over dispersion is modeled by the negative binomial regression model which is more flexible than the Poisson model [20-22]. The probability mass function for a negative binomial random variable is given by;

$$
p\left(y_{i}, \mu_{i}, \alpha\right)=\frac{\Gamma\left(y_{i}+\frac{1}{\alpha}\right)}{y_{i !} \Gamma\left(\frac{1}{\alpha}\right)}\left(1+\alpha \mu_{i}\right)^{-\frac{1}{\alpha}}\left(1+\frac{1}{\alpha \mu_{i}}\right)^{-y_{i}}, y_{i>0}
$$

Where $\alpha$ is the overdispersion parameter and $\Gamma($.$) is the gamma function when \alpha=0$. The negative binomial distribution adds an explicit error term $\varepsilon$ to the Poisson regression model, as follows; $\mu_{i}=\exp \left(\eta_{i}+\varepsilon_{i}\right)=\exp \left(\eta_{i}\right)^{*} \exp \left(\varepsilon_{i}\right)$ 


\section{Two-level count regression model}

The multilevel Poisson regression model for a count $Y_{i j} \quad$ on the $i^{\text {th }}$ level 1 in $j^{\text {th }}$ level 2 with $\mathrm{C}$ varying exposure rate can be written as: $Y_{i j} / \lambda_{i j}=\operatorname{Poisson}\left(C_{i j}, \lambda_{i j}\right)$. Then the two-level Poisson regression model containing $\mathrm{p}$ lower level and q higher level predictors is given by;

$\ln \left(\lambda_{i j}\right)=\eta_{i j}=\beta_{00}+\sum_{i=1}^{p} \beta_{i 0} x_{i j}+\sum_{j=1}^{q} \beta_{0 j} Z_{j}+\sum_{j=1}^{q} \sum_{i=1}^{p} \beta_{i j} x_{i j} Z_{j}+U_{0 j}+\sum_{j=1}^{q} \sum_{i=1}^{p} U_{i j} x_{i j}$

Where; $\gamma_{00}$ represents the overall log rate of birth across all women and enumeration areas $\mathrm{u}_{0 \mathrm{j}}$ represents the residual errors at the enumeration area with respective variances as $\sigma^{2} u_{0}$

$\beta_{i 0}$ and $\beta_{0 j}$ Represent lower level and higher level fixed effects respectively with corresponding predictors and $\beta_{i j} \quad$ represents the interaction effect of higher level and lower level predictors on the response variable.

In the Poisson regression model, the variance of the outcome variable is assumed to be equal to the mean. When the observed variance is much larger than expected under the Poisson model, we have over-dispersion. One way to model over-dispersion is to add an explicit error term to the model. Then the negative binomial model adds an explicit error term $\varepsilon$ to the model, as follows; $\mu_{i j}=\exp \left(\eta_{i j}+\varepsilon_{i j}\right)=\exp \left(\eta_{i j}\right) * \exp \left(\varepsilon_{i j}\right)$

\section{Results}

Among the random sample of 6141 women in the country, 27150 births were recorded based on EDHS 2016 report. The histograms were extremely picked at the beginning, but higher observations (larger number of children per woman) were observed less frequently. This ended up in a positively skewed distribution of the data. Extra screening of fertility showed that the variance (11.873) was higher than the mean (4.42), which implies the existence of over-dispersion, this means the data could be fitted better by a negative binomial regression model. 


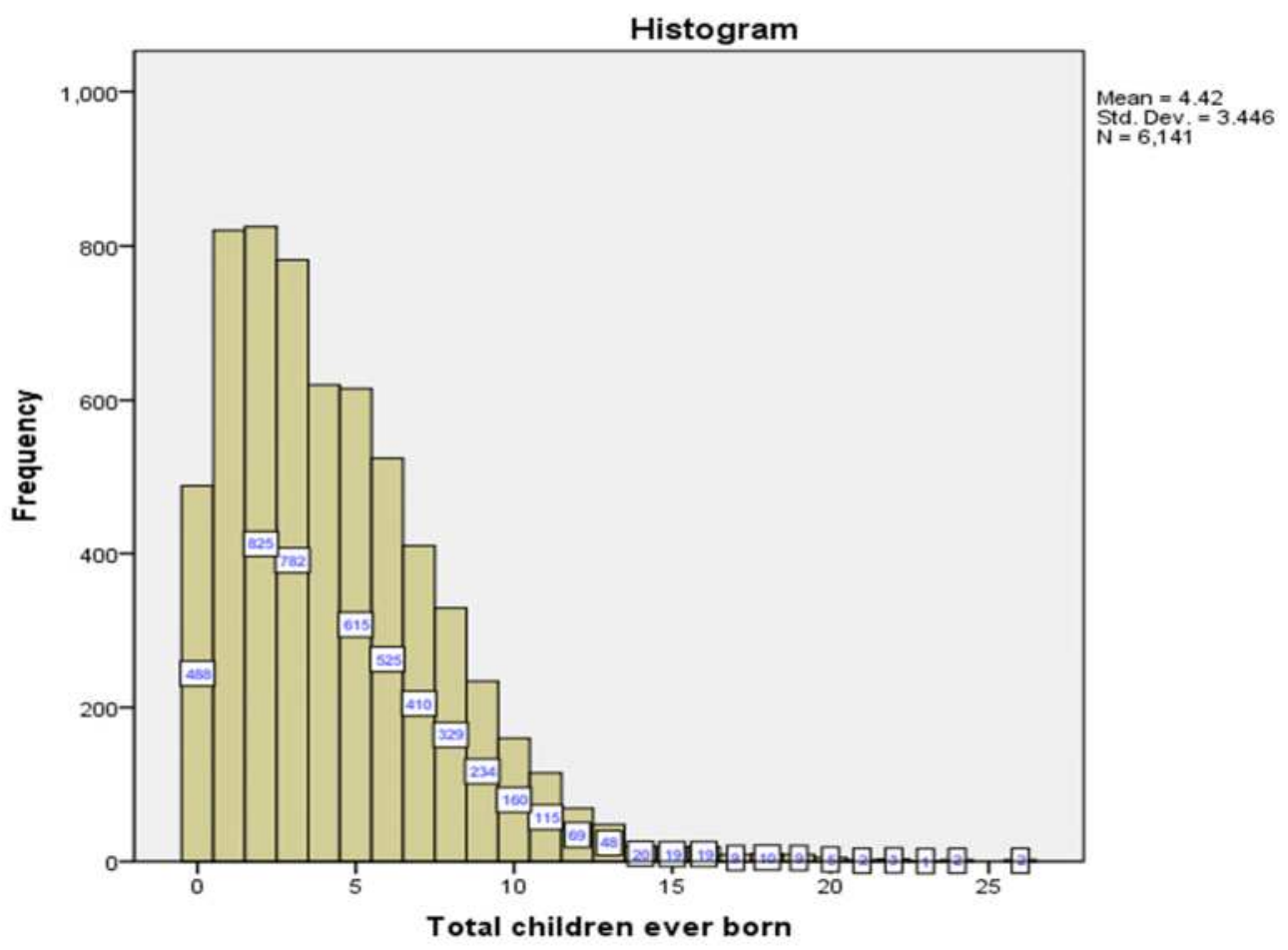

Figure 1 Histogram for the numbers of children ever born

\section{Number of children ever born and its socio-demographic and economic features}

The majority, $77.3 \%$ of women were selected from rural areas of Ethiopia. Most of the women (52.2\%) used traditional methods of contraception, while $44 \%$ of them did not use any method, while the remaining (3.8\%) uses modern methods of contraception. The majority of these sample women were illiterate (58.3\%), Muslims (40.9\%), and poorest income level (35.4\%) relative to other corresponding labels of a factor. Moreover, statistically significant chi-square statistic implies that the observed number of the count was consistent with the expected number of counts across each label of the factor table 1. 
Table 1 Descriptive Statistics

\begin{tabular}{|c|c|c|c|c|}
\hline \multicolumn{5}{|c|}{ Descriptive Statistics } \\
\hline variable & categories & Frequency & Percent & $\chi^{2}-$ value(P-value $)$ \\
\hline \multirow{2}{*}{$\begin{array}{l}\text { Place of } \\
\text { residence }\end{array}$} & Urban & 1393 & 22.7 & \multirow[t]{2}{*}{$1832.93(<.0001)$} \\
\hline & Rural & 4748 & 77.3 & \\
\hline Age at first birth & In year & & & \\
\hline \multirow{3}{*}{$\begin{array}{l}\text { Contraception } \\
\text { method }\end{array}$} & Not used & 2705 & 44 & \multirow[t]{3}{*}{$2471.859(<.0001)$} \\
\hline & Modern & 233 & 3.8 & \\
\hline & Traditional & 3203 & 52.2 & \\
\hline \multirow{4}{*}{$\begin{array}{l}\text { Women's } \\
\text { educational level }\end{array}$} & Illiterate & 3578 & 58.3 & \multirow[t]{4}{*}{$4460.13(<.0001)$} \\
\hline & Primary & 1774 & 28.9 & \\
\hline & Secondary & 481 & 7.8 & \\
\hline & Higher & 308 & 5 & \\
\hline \multirow[t]{6}{*}{ Religion } & Orthodox & 2386 & 38.8 & \multirow[t]{6}{*}{$6840.478(<.0001)$} \\
\hline & Catholic & 39 & 0.6 & \\
\hline & Protestant & 1140 & 18.6 & \\
\hline & Muslim & 2508 & 40.9 & \\
\hline & Traditional & 39 & 0.6 & \\
\hline & Others & 29 & 0.5 & \\
\hline \multirow[t]{5}{*}{ Wealth index } & poorest & 1575 & 25.6 & \multirow[t]{5}{*}{$372.909(<.0001)$} \\
\hline & Poorer & 1040 & 16.9 & \\
\hline & middle & 955 & 15.6 & \\
\hline & Richer & 953 & 15.5 & \\
\hline & Richest & 1618 & 26.4 & \\
\hline
\end{tabular}

Proceeding birth month interval 


\section{Model selection criteria}

As compared to other models, the negative binomial regression model has a minimum value for the fit statistics than the remaining models. Consequently, it is selected as the best model for the total number of children ever born among married women in Ethiopia.

Table 2 Model Selection

\begin{tabular}{lllll}
\hline \multirow{2}{*}{ Fit statistics } & \multicolumn{4}{c}{ Model } \\
\cline { 2 - 5 } & Poisson & Negative Binomial & ZIP & ZINB \\
\hline AIC & 22553.6349 & 22080.5602 & 22602 & 22113 \\
\hline BIC & 22669.6574 & 22203.0284 & 22705 & 2222
\end{tabular}

Fitting Two-level negative binomial regression model

When we are interested to analyze on a single level by standard regression models the model fitting is quite easy, but when we have hierarchical data with the predictors at the different levels, the process of model fitting should consider a series of steps. While the most crucial step for multilevel analysis is fitting the model with no predictors (i.e. the intercept only model)

$\mathrm{Y}_{\mathrm{ij}}=\gamma_{00+}+\mathrm{u}_{0 \mathrm{j}}+\mathrm{e}_{\mathrm{ij}} \quad$ where:

$\mathrm{Y}_{\mathrm{ij}}$ represents total number of children ever born from $i^{\text {th }}$ women in ${ }^{\text {th }}$ enumeration area,

$\gamma_{00}$ represents the overall log rate of birth across all women and enumeration areas.

$\mathrm{u}_{0 \mathrm{j} \&} \mathrm{e}_{\mathrm{ij}}$ represents the residual errors at the enumeration areas and women level respectively with their respective variances as $\sigma^{2} u_{0}$ and $\sigma^{2} \varepsilon_{0} \quad$ where $\varepsilon_{i j} \sim N\left(0, \sigma_{\varepsilon}^{2}\right)$ 
Table 3 Intercept only model

\section{Estimates for fixed effects}

\begin{tabular}{lrrrrrrr}
\hline Effect & $\widehat{\boldsymbol{\beta}}(\boldsymbol{\operatorname { E x p }}(\widehat{\boldsymbol{\beta}}))$ & $\mathrm{SE}$ & $\mathbf{t}$ Value & $\operatorname{Pr}>|\mathbf{t}|$ & Alpha & Lower & Upper \\
\hline Intercept & $1.4864(4.42)$ & 0.009945 & 149.47 & $<.0001$ & 0.05 & 1.4669 & 1.5059 \\
\hline
\end{tabular}

Estimates for random effects

Cov Parm Estimate

Intercept $\left(\mathrm{U}_{\mathrm{oj}}\right) \quad 0.5748$

$\begin{array}{ll}\text { Scale }\left(e_{i j}\right) & 0.2937\end{array}$

The residual error variance at the women and enumeration area level was estimated to be $0.2937 \&$ 0.5748 respectively as result of the maximum likely hood estimation. We can conclude that the overall rate of birth across all women and all enumeration areas is was 4.42 and that there is more variation among the different enumeration areas (0.5748) than within the enumeration areas (0.2937). This will be discussed further when we calculate the intra-class correlation $(\rho)$ for this model below. Intra-class correlation represents the proportion of variance explained due to the grouping structure.

$$
\rho=\frac{\sigma^{2} u_{0}}{\sigma^{2} \varepsilon_{0}+\sigma^{2} u_{0}}=\frac{0.5748}{0.2937+0.5748}=0.66
$$

This result implied that $66 \%$ of the fertility variation was at the enumeration area level and the remaining $34 \%$ was between women. Then the final two-level random intercept and slope negative binomial regression model was fitted through all the significant predictors in the univariable analysis. Accordingly, Appendix I displays the results of the final model with fixed and random effect estimates. Among the predictors in the final model contraception method used, residence, educational level of women, women's age at first birth, and the proceeding birth interval were the 
major predictors for fertility among married women in Ethiopia. Moreover, the estimates from the random effect result revealed that there was more variation between the different enumeration areas $(0.06512)$ than within the enumeration areas $(0.05255)$, furthermore, the variation among rural and urban areas was more significant (0.08982) on the number of children ever born among married women in Ethiopia.

\section{Discussion}

In this study, secondary data from 6141 randomly selected women were assessed using two-level negative binomial regression model, and significant factors associated with fertility among married women in Ethiopia were identified.

The estimated fixed intercept was 1.4474 , which represents the overall rate of birth was $e^{1.4474}=$ 4.25(p-value $<0.0001)$ across all the enumeration areas and all women. Based on the result from this study, contraception use has a significant effect on the rate of birth among married women in Ethiopia, accordingly, the rate of birth among women with no contraception used and modern contraception was 1.19 and 1.16 respectively times the rate of birth among women with traditional methods of contraception while keeping all other variables constant. The result is coherent with the study done by [23] where ever use of contraception reduced the rate of birth. The rate of birth among women from rural areas was 1.14 times the rate of birth among women from urban areas, the result was consistent with the study conducted by $[7,8,24,25]$ where rural women desire to have more children than urban women. The rate of birth among women with no and primary education was 1.52 and 1.2 respectively times rate of birth with secondary education, moreover, no statistically significant difference was observed on the rate of birth by women with higher and secondary education levels. The result is conformable with $[10,24,26]$ where the increasing the 
educational level of women reduced the rate of birth. A one year increase in the age at first birth of women' results in a 0.0017 decrement in the log rate of birth, the result is consistent with the finding of $[10,24,27])$ where the older the age at first birth of women the lower number of children ever born per woman will be. Moreover, a one-month increase in the proceeding birth interval of women resulted in a 0.01209 decrement in the log rate of birth, the result was consistent with the findings of [28, 29], where increasing proceeding birth interval resulted in the reduced number of children ever born.

\section{Conclusions}

This study targeted the application of a two-level count regression model on the determinants of fertility among married women in Ethiopia. The source of the data for this study was the fourth (2016) demographic and health survey of Ethiopia. The survey was implemented by the Central Statistical Agency (CSA) with support from the Ministry of Health. The sampling design for EDHS 2016 was a two-stage stratified cluster sampling design. The histograms for the total number of children ever born has a positively skewed distribution extremely picked at the beginning. Additional screening of the data showed that the variance of an outcome was greater than the mean which is an implication of over-dispersion, then the data could be fitted better by a negative binomial regression model. Inferentially, the negative binomial regression model fits the data well due to the minimum value for the fit statistics than the remaining models. The interceptonly model demonstrated that there is more variation among the different enumeration areas than within the enumeration areas. Among the predictors within the final two-level negative binomial regression model, contraception method used, residence, education level of women, women's age at first birth, and Proceeding birth interval were significant predictors for fertility among married women in Ethiopia at 5\%level of significance. Finally, since more variation in fertility is observed 
between the enumeration areas, application of standard models by ignoring this variation ought to embrace spurious results, then multilevel medaling is recommended for such types of hierarchical data.

\title{
Limitations
}

This study was a two-level analysis of factors associated with fertility in Ethiopia, this is due to the inaccessibility of regional-level factors. So, policymakers of CSA should include regional level variables for better future results.

\author{
Abbreviations \\ AIC: Akaike Information Criteria, BIC: Bayesian Information Criteria, CSA: Central Statistical \\ Agency, EA : Enumeration Area, EDHS: $\quad$ Ethiopian Demographic and Health \\ Survey, GLM: General Linear Regression Model, ICF: International Consultancy \\ Fund, LL: Log-Likelihood, LRT: Likelihood Ratio Tests, NB: Negative Binomial, NBRM: \\ Negative Binomial Regression Models, PRM: Poisson Regression Models, TWFR: Total Fertility \\ Rate
}

\section{Declarations}

The author affirms that this study was a result of own real work. All documents used for writing it were appositely acknowledged.

\section{Ethics Consent to Participate}

This study is a secondary data analysis of EDHS, which is publicly available. The methodologies of DHS were carried out in conformity with relevant ethical guidelines and regulations. Ethical clearance was obtained from the Ethiopian Public Health Institute (the former Ethiopian Health and Nutrition Research Institute (EHNRI) Review Board, the National Research Ethics Review 
Committee (NRERC) at the Ministry of Science and Technology, the Institutional Review Board of international classification of functioning, disability and health, and the United States Centers for Disease Control and Prevention (CDC). Written agreements was made from women or caregivers and data were collected anonymously at the time of data collection during the EDHS 2016.

\section{Consent to Publish}

Not Applicable

\section{Availability of Data and Materials}

The data set used for this study was women's data of EDHS 2016. The data was accessed from the Measure DHS website (http://www.measuredhs.com).

\section{Competing Interests}

No competing interests were declared by the authors.

\section{Funding}

The author does not have support or funding to report.

\section{Authors' Contributions}

NM wrote the proposal, analyzed the data and manuscript writing. NM browse and approved the most recent manuscript.

\section{Acknowledgments}

The author would like to thank Ethiopia CSA for the freely availability of the data to research purposes. 


\section{References}

1. Murray, C.J., et al., Population and fertility by age and sex for 195 countries and territories, 1950-2017: a systematic analysis for the global burden of disease study 2017. The Lancet, 2018. 392(10159): p. 1995-2051.

2. Drummond, M.P., V. Thakoor, and S. Yu, Africa rising: harnessing the demographic dividend. 2014: International Monetary Fund.

3. Demographic, E., Health survey: Addis Ababa. Ethiopia and Calverton, Maryland, USA: central statistics agency and ORC macro, 2011. 2011.

4. Shapiro, D. and T. Gebreselassie, Fertility transition in sub-Saharan Africa: falling and stalling. African Population Studies, 2008. 23(1).

5. Hailemariam, A., S. Alayu, and C. Teller, The National Population Policy (NPP) of Ethiopia: achievements, challenges and lessons learned, 1993-2010, in The Demographic Transition and Development in Africa. 2011, Springer. p. 303-321.

6. Keneni, G., et al., Genetic diversity and population structure of Ethiopian chickpea (Cicer arietinum L.) germplasm accessions from different geographical origins as revealed by microsatellite markers. Plant Molecular Biology Reporter, 2012. 30(3): p. 654-665.

7. Ayele, D.G., Determinants of fertility in Ethiopia. African health sciences, 2015. 15(2): p. 546-551.

8. Mekonnen, W. and A. Worku, Determinants of fertility in rural Ethiopia: the case of Butajira Demographic Surveillance System (DSS). BMC public health, 2011. 11(1): p. 16.

9. Melese, Z.Y. and L.B. Zeleke, Factors Affecting Children Ever Born Among Reproductive Aged Women in Ethiopia; Data from Edhs 2016. World, 2020. 5(3): p. 66-75. 
10. Eyasu, A.M., Multilevel modeling of determinants of fertility status of married women in Ethiopia. American Journal of Theoretical and Applied Statistics, 2015. 4(1): p. 19-25.

11. Goldstein, H., Multilevel models in education and social research. 1987: Oxford University Press.

12. Tom, A., T.A.S.R.J. Bosker, and R.J. Bosker, Multilevel analysis: an introduction to basic and advanced multilevel modeling. 1999: sage.

13. Harttgen, K. and M. Misselhorn, A multilevel approach to explain child mortality and undernutrition in South Asia and Sub-Saharan Africa, 2006, IAI Discussion Papers.

14. Raudenbush, S.W. and A.S. Bryk, Hierarchical linear models: Applications and data analysis methods. Vol. 1. 2002: sage.

15. Khan, H.R. and E. Shaw, Multilevel logistic regression analysis applied to binary contraceptive prevalence data. Journal of Data Science, 2011. 9: p. 93-110.

16. Long, J.S. and J. Freese, Regression models for categorical dependent variables using Stata. Vol. 7. 2006: Stata press.

17. Sano, Y., et al., Working with count data: Practical demonstration of Poisson, negative binomial and zero-inflated regression models. Special Session on Zero Inflated Modeling at the Theory Construction and Research Methodology, Phoenix, AZ, 2005.

18. Atkins, D.C. and R.J. Gallop, Rethinking how family researchers model infrequent outcomes: a tutorial on count regression and zero-inflated models. Journal of Family Psychology, 2007. 21(4): p. 726.

19. Karazsia, B.T. and M.H. Van Dulmen, Regression models for count data: illustrations using longitudinal predictors of childhood injury. Journal of pediatric psychology, 2008. 33(10): p. 1076-1084. 
20. Murphy, D.A., et al., Predictors of antiretroviral adherence. AIDS care, 2004. 16(4): p. $471-484$.

21. Hilbe, J.M., Negative binomial regression. 2011: Cambridge University Press.

22. Lawless, J.F., Negative binomial and mixed Poisson regression. The Canadian Journal of Statistics/La Revue Canadienne de Statistique, 1987: p. 209-225.

23. Bongaarts, J., The effect of contraception on fertility: Is sub-Saharan Africa different? Demographic Research, 2017. 37: p. 129-146.

24. CHOWDHURY, M.H. and D.J. MOLOY, A STATISTICAL ANALYSIS TO IDENTIFY POTENTIAL FACTORS OF FERTILITY IN BANGLADESH. Journal of Science and Technology, 2014. 4(1): p. 65-78.

25. Tadesse, F. and D. Headey, Urbanization and fertility rates in Ethiopia. Ethiopian Journal of Economics, 2010. 19(2): p. 35-72.

26. Breierova, L. and E. Duflo, The impact of education on fertility and child mortality: Do fathers really matter less than women?, 2004, National bureau of economic research Cambridge, Mass., USA.

27. Kabeer, N., Ideas, economics and'the sociology of supply': explanations for fertility decline in Bangladesh. Journal of Development Studies, 2001. 38(1): p. 29-70.

28. Srinivasan, K., Birth interval analysis in fertility surveys. 1980: ISI.

29. Rabbi, A.M.F., et al., Determinants of birth spacing and effect of birth spacing on fertility in Bangladesh. Dhaka University Journal of Science, 2013. 61(1): p. 105-110. 


\section{Appendix I}

Table 4 Final two-level negative binomial regression model

\begin{tabular}{|c|c|c|c|c|c|c|c|}
\hline \multicolumn{8}{|c|}{ Solutions for Fixed Effects } \\
\hline Variable & categories & $\widehat{\boldsymbol{\beta}}$ & SE & $\begin{array}{l}\operatorname{Exp}( \\
\widehat{\boldsymbol{\beta}}))\end{array}$ & $\operatorname{Pr}>|\mathbf{t}|$ & Lower & Upper \\
\hline Intercept & & 1.4474 & 0.1063 & 4.25 & $<.0001$ & 1.2389 & 1.6558 \\
\hline \multirow{3}{*}{$\begin{array}{l}\text { Contraception } \\
\text { use }\end{array}$} & No & 0.1747 & 0.0393 & 1.19 & $<.0001$ & 0.09764 & 0.2517 \\
\hline & $\begin{array}{l}\text { modern } \\
\text { method }\end{array}$ & 0.1500 & 0.0185 & 1.16 & $<.0001$ & 0.1138 & 0.1862 \\
\hline & $\begin{array}{l}\text { traditional } \\
\text { method }\end{array}$ & 0 & . & $\cdot$ & . & . & \\
\hline \multirow[t]{2}{*}{ Residence } & Rural & 0.1322 & 0.0344 & 1.14 & 0.0001 & 0.06482 & 0.1996 \\
\hline & Urban & 0 & . & . & . & . & \\
\hline \multirow[t]{6}{*}{ Wealth index } & Poorest & 0.005339 & 0.0343 & 1.00 & 0.8763 & -0.06190 & 0.07258 \\
\hline & Poorer & 0.01027 & 0.0353 & 1.01 & 0.7713 & -0.05900 & 0.07955 \\
\hline & Middle & 0.02772 & 0.0355 & 1.03 & 0.4346 & -0.04182 & 0.09726 \\
\hline & Richer & 0.07319 & 0.0347 & 1.08 & 0.0352 & 0.005083 & 0.1413 \\
\hline & Richest & 0 & . & . & $\cdot$ & & \\
\hline & & & & & & 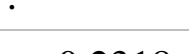 & $\cdot$ \\
\hline \multirow[t]{6}{*}{ Religion } & Catholic & 0.03312 & 0.1351 & 1.03 & 0.8064 & -0.2318 & 0.2980 \\
\hline & Muslin & 0.09213 & 0.0872 & 1.10 & 0.2905 & -0.07872 & 0.2630 \\
\hline & Orthodox & 0.02384 & 0.0881 & 1.02 & 0.7867 & -0.1489 & 0.1965 \\
\hline & Other & 0.07837 & 0.1381 & 1.08 & 0.5704 & -0.1924 & 0.3491 \\
\hline & Protestant & 0.08597 & 0.0887 & 1.09 & 0.3325 & -0.08792 & 0.2599 \\
\hline & Traditional & 0 & . & . & . & . & \\
\hline \multirow[t]{4}{*}{$\begin{array}{l}\text { Education } \\
\text { level }\end{array}$} & $\begin{array}{l}\text { No } \\
\text { education }\end{array}$ & 0.4157 & 0.0460 & 1.52 & $<.0001$ & 0.3256 & 0.5058 \\
\hline & Primary & 0.1788 & 0.0467 & 1.20 & 0.0001 & 0.08734 & 0.2703 \\
\hline & Higher & -0.0514 & 0.0712 & 0.95 & 0.4705 & -0.1911 & 0.08824 \\
\hline & Secondary & 0 & . & . & . & . & . \\
\hline
\end{tabular}




\begin{tabular}{|c|c|c|c|c|c|c|}
\hline $\begin{array}{l}\text { Age at first } \\
\text { birth }\end{array}$ & -0.0016 & 0.0004 & 0.10 & $<.0001$ & -0.00248 & -0.00102 \\
\hline $\begin{array}{l}\text { Proceeding } \\
\text { birth interval }\end{array}$ & -0.0121 & 0.0016 & 0.99 & $<.0001$ & -0.01521 & -0.00897 \\
\hline \multicolumn{7}{|c|}{ Solutions for random effects } \\
\hline Cov parm & \multicolumn{6}{|c|}{ Estimate } \\
\hline Intercept $\left(\mathbf{U}_{\mathbf{o j}}\right)$ & \multicolumn{6}{|l|}{0.06512} \\
\hline Residence & \multicolumn{6}{|l|}{0.08982} \\
\hline Scale $\left(\mathbf{e}_{\mathbf{i j}}\right)$ & \multicolumn{6}{|l|}{0.05255} \\
\hline
\end{tabular}

